\title{
The landscape as a source of inspiration for painters: paintings as a source of inspiration for land development?
}

\author{
E. Bos ${ }^{1}$, P. van der Jagt ${ }^{2} \&$ W. Timmermans ${ }^{3}$ \\ ${ }^{1}$ LEI, The Netherlands \\ ${ }^{2}$ Alterra, The Netherlands \\ ${ }^{3}$ Van Hall Larenstein, The Netherlands
}

\begin{abstract}
In today's landscapes, development policy is mainly directed towards the blacktailed and bar-tailed godwit. We are of the opinion however that the development of the landscape should be more inspired by famous works of art. Try not to be too concerned: if you look closely, godwits are frequently incorporated into these masterpieces. The Netherlands, as a pioneer in landscape paintings, has had a long tradition of recording them on canvas, and agricultural landscapes have always been a key subject. Paintings are therefore a significant source of information as to how the agricultural landscape looked in former times and are thus important when considering the cultural historical value of the cultivated landscape. But the question 'Is there more?' still arises. Apart from the historical register, can these works of art have a more significant meaning for the Netherlands? In this article we will first investigate the relationship between art and the Dutch landscape, and will demonstrate that in the past the romanticism of the disappearing natural landscape was an important source of inspiration. We will continue by investigating the interaction between art and the economy.
\end{abstract}

Keywords: Dutch cultural-history, paintings, landscape, land development, economic interaction.

\section{Art and the Dutch landscape}

The Netherlands is an outstanding example of a painter's paradise. Together with Italy and France it is one of the few countries in the world that has produced at 
least one world-renowned painter every hundred years since the fourteenth century. In fact, painting is regarded internationally as the most creative core skill of the Netherlands. It was also the first country in which painters specialised in landscapes, and such paintings began to be associated with the Netherlands from the seventeenth century onwards.

World-renowned painters such as Jacob van Ruysdael and Meindert Hobbema immortalised the landscape on canvas. As well as the romanticised fantasy landscapes, it was mainly the agricultural landscapes that were portrayed.

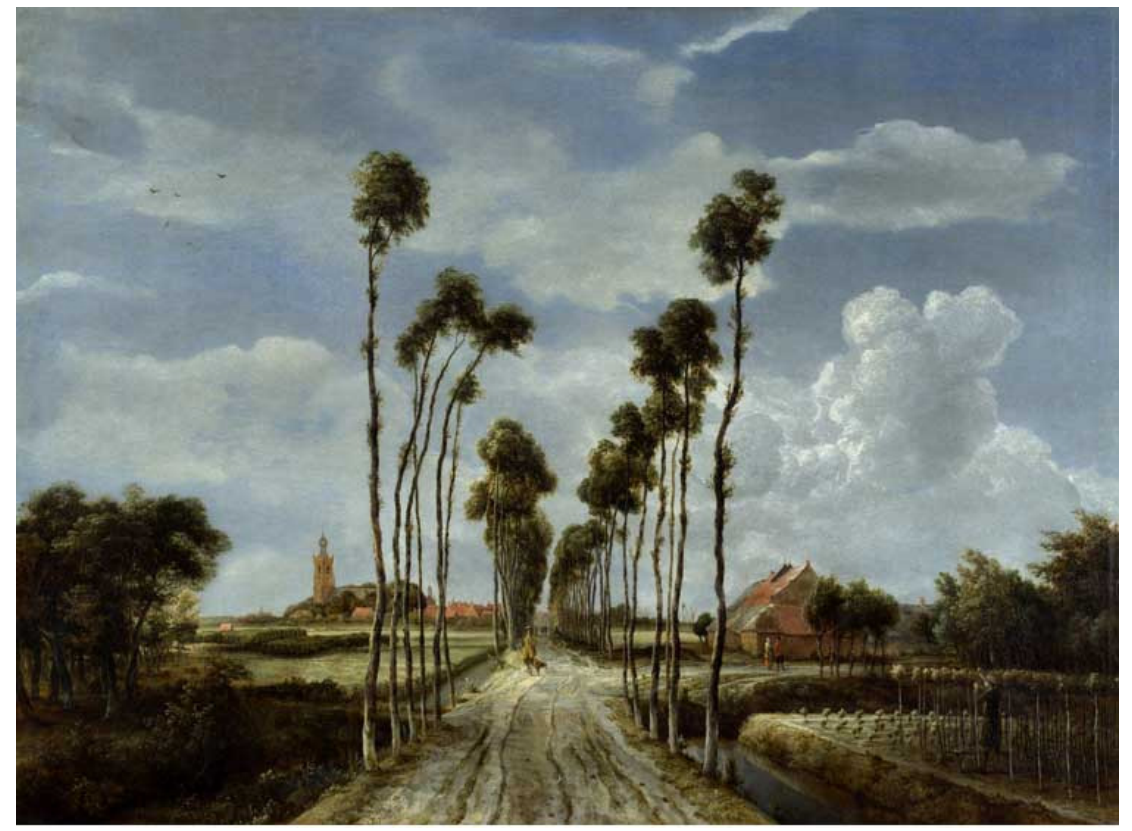

Figure 1: Meindert Hobbema, source: [1].

For example, looking at paintings by Ruysdael, we can get a clear image of the landscape around Haarlem, 't Gooi and Ootmarsum in the seventeenth century. These paintings clearly illustrate the extensive grasslands as well as the vastness of the landscape.

The eighteenth century was a time of economic decline in the Netherlands, and was reflected in a sharp fall in the number of painters. During the nineteenth century however, the industrial revolution also reached the Netherlands, resulting in a rise in the number of painters. The invention of tubes (for the paint) made it easier for painters to work outdoors, allowing them to produce almost photographic images of the landscape. Attention was increasingly shifting from the landscape to the activities that took place in that landscape. The artists zoomed in more and more to agricultural activities that were going on against a background of the landscape.

In the mid-nineteenth century, the Dutchman Jongkind was recognised as one of the forerunners of the world-famous impressionists. In addition to seascapes 
and townscapes, his main interest was to paint agricultural landscapes. In 1863 Jongkind met the much younger Claude Monet, who since then began to paint in the characteristic shades of the impressionists. Another world-renowned nineteenth century Dutchman famous for his landscapes is Van Gogh. He painted many Dutch landscapes and rural scenes, especially in Drenthe and in the vicinity of The Hague. The Impressionists obscured real nature by their own personal interpretations. The photographic element disappeared, making room for expressing emotion. The experience of the landscape became the focus of attention.

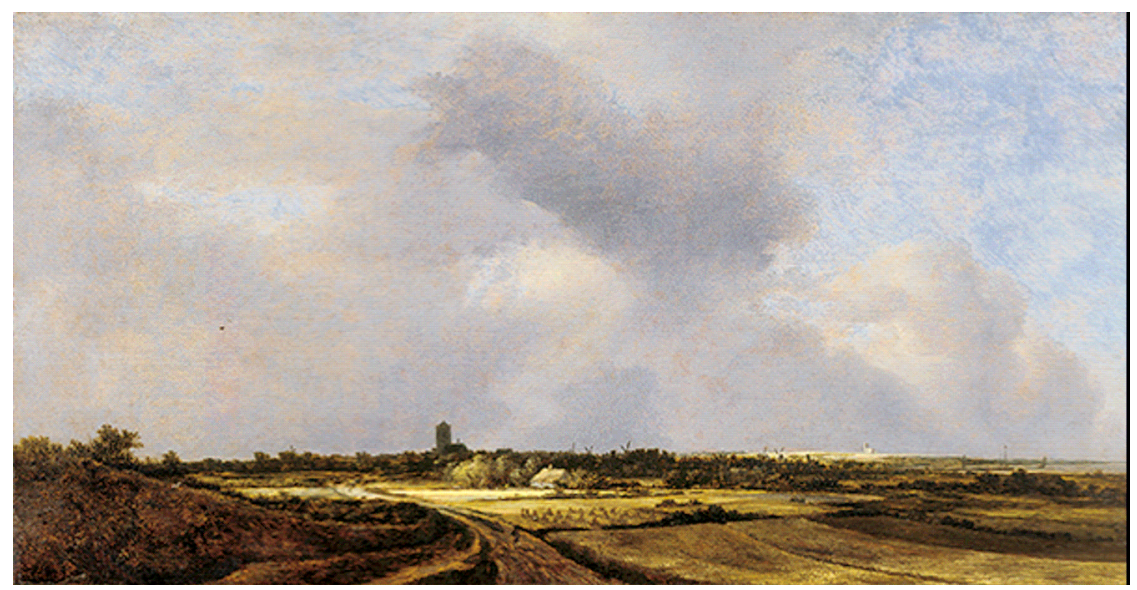

Figure 2: Jacob van Ruysdael, source: [2].

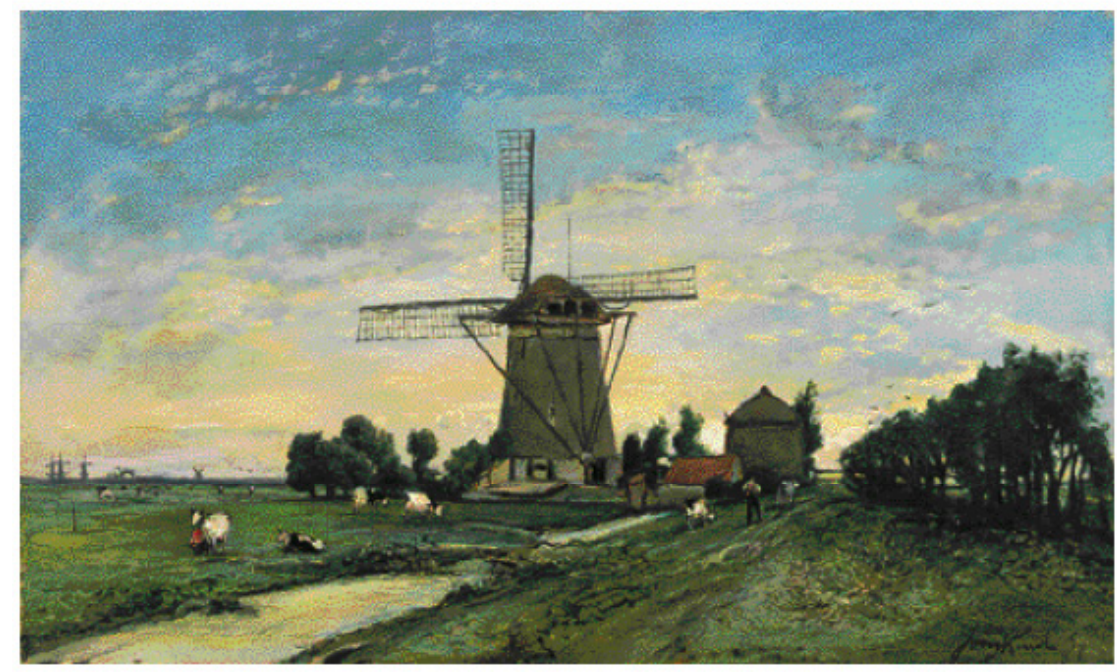

Figure 3: Johan Barthold Jongkind, source: [3]. 


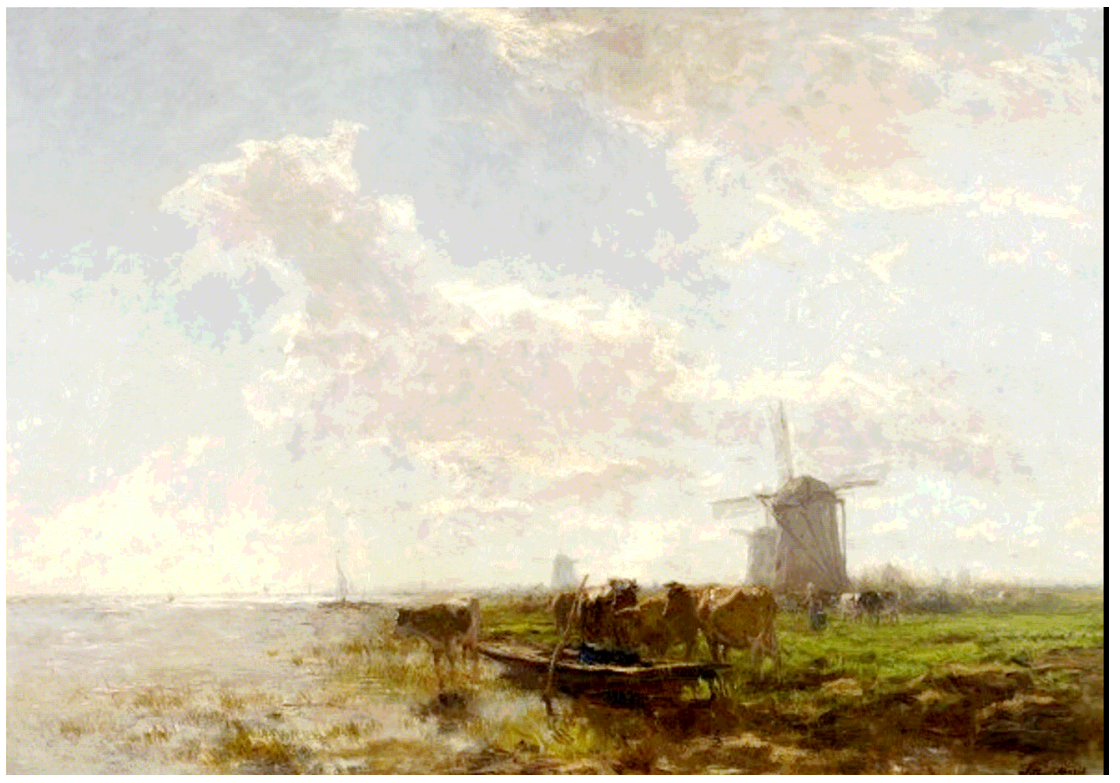

Figure 4: Willem Maris, source: [4].

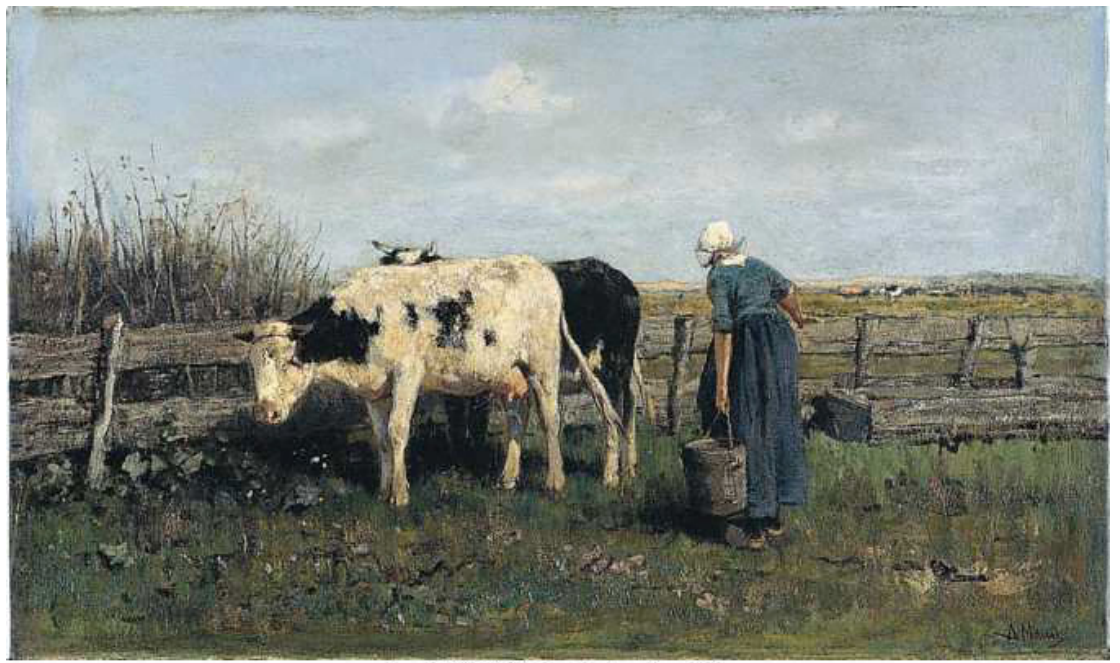

Copyright $\Theta 20$

Figure 5: $\quad$ Anton Mauve, source: [1].

In the second half of the nineteenth century, and beginning of the twentieth, a group of painters emerged who mainly concentrated on agricultural landscapes.

This group was known as The Hague School, which had a noteworthy auxiliary branch in 't Gooi. The landscapes painted by these artists were much in demand in the United States and the United Kingdom. Painters in 't Gooi, the 
most well known of which were Anton Mauve and Jozef Israëls, concentrated entirely on agricultural landscapes and rural life.

Later, Piet Mondriaan also established himself in 't Gooi where he could paint rural scenes.

In recent times, several well-known painters, for example Rien Poortvliet, Pieter Verstappen, Ton Schulten and Hans Parlevliet used the Dutch agricultural landscape as a spearhead for their work.

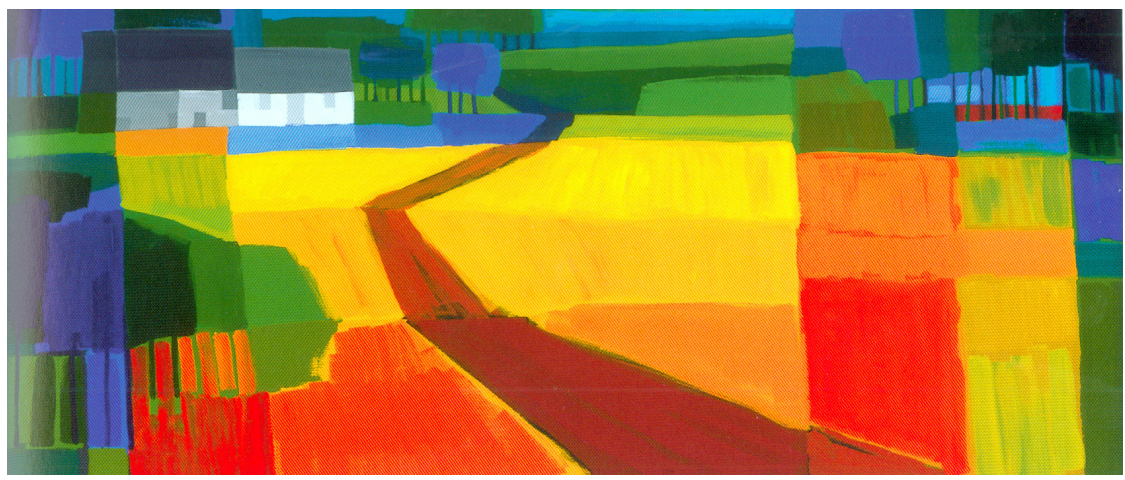

Figure 6: Ton Schulten, source: [5].

However, it was not only Dutch painters who were inspired by their own landscape, well-known painters from other countries also immortalised it. The previously mentioned impressionist, Claude Monet spent time in the Netherlands where, amongst other things, he painted agricultural landscapes, such as the tulip fields. His contemporary Emanuel Manet also painted in the Netherlands, as did William Singer, after whom the Singer Museum in Laren was named, and Wallisy Kandinsky who also captured Dutch landscapes on canvas.

\section{Interaction with the economy?}

In many aspects, landscape art is linked to the Dutch economy. In the case of The Hague School, landscapes that were on the point of being affected by the heaving breath of industrialisation were often painted. At the same time painting is dependent upon the economy. Economic growth provides a favourable climate for art. Historically, we can see this happening time and time again. In Italy, the fifteenth and sixteenth centuries were not only a period of great economic growth, but the number of Italian painters in this period was also greater than ever before. We can see a similar picture for the Netherlands in the seventeenth century and in France from the nineteenth century.

As far as interaction with the economy is concerned, it is also interesting to ask whether the value of a painting can tell us something about the economic value of the landscape that had been depicted. It is of course obvious that this will depend on the talent of the painter, but it is remarkable that a country such as France, a prototype of landscape art, is a favourite holiday destination for 
tourists from the low-countries in particular. Is it not possible therefore that art could and still could in fact stimulate the economy? Implicitly the painters in ' $t$ Gooi depicted the region as a strikingly picturesque environment, which has contributed to the attraction of ' $t$ Gooi to those from the higher income groups. Furthermore, the most well-known Dutch abstract landscape painter, Ton Schulte, concentrated on the landscapes in the region of Ootmarsum, which is becoming more and more of a national centre for art galleries. It is probably no coincidence that Van Ruysdael had already discovered Ootmarsum and its environs in the seventeenth century.

\section{Discussion}

The current economy can also profit from the Dutch tradition of landscape art. The Dutch landscape has inspired many famous painters, such as those from The Hague School, whose paintings are still recognisable in several locations, allowing The Hague, for instance, to be profiled as a city with a rich cultural history, and thus becoming especially attractive to companies employing expatriots who have a potential cultural interest in the city. As a result, the surrounding land continues to be attractive to local residents. The story of The Hague School can serve as a source of inspiration for achieving a cultural stratum in the modern landscape. Land conservation and planning should, therefore, be able to tune in to the experience recorded by artists of the past. The combination of the landscape and the paintings of this landscape can offer new possibilities.

Landscape planners should be able to profile this cultural historical value. For example, illustrated signs could be erected at places that had been painted centuries ago. Visitors to the area would thus be made more aware of the cultural historical value of the landscape. Such signs could also give the visitor a good idea as to how the location has changed over the course of time, or even in fact how it has remained much the same. Using this strategy, which would be relatively inexpensive, 'landscape painters routes' could be created, for example in the neighbourhood of The Hague or 't Gooi. In this way the cultural connection between the city (museums) and the countryside could be marketed more visibly and emphatically.

A more rigorous approach could be to bring the landscape back to the form in which it was portrayed in the old paintings. Such an approach has already been made in the United Kingdom, guided by works of painters such as Constable, who was in fact an admirer of Van Ruysdael. It is obvious though that such an approach would be considerably more expensive.

Landscape and rural planning should thus be more broadly oriented, and the conservation and planning of such areas should be concentrating much more on the great cultural value so cherished by our world-renowned painters. The fact is that the old landscape itself, upon which the National Ecological Network (NEN) to its very roots is so romantically focussed while at the same time limiting the number of its target species, should be the main objective for landscape investment. The godwits would then return with no need for further human intervention. 


\section{Conclusion}

From a historical viewpoint the Netherlands has a unique place in landscape art. Not only did landscape painting begin in the Netherlands, but it has also been a source of inspiration for many well-known Dutch painters, as well as those from further afield. In this respect the Dutch landscape is well regarded all over the world. From that aspect alone, our agricultural landscape can be regarded as a cultural historical heritage. The value of the whole is greater than the sum of the parts. Landscape planning inspired by art presents fresh possibilities, which can bring the city and the countryside closer together thus broadening the functions of the landscape with strata that can fire the imagination. One recommendation for land development is to direct the conservation and planning of regions explicitly to the cultural historical values, so lovingly cherished and preserved for centuries by the artists who painted them.

\section{References}

[1] http://www.nationalgallery.org.uk

[2] www.museothyssen.org

[3] www.schelfhout.nl

[4] www.gemeentemuseum.nl

[5] Waanders Uitgeverij, Zwolle/Ton Schulten, Ootmarsum 